\title{
A subset of systemic lupus erythematosus with progressive cystic bone lesions
}

\author{
Leena Laasonen, Marianne Gripenberg, Ritva Leskinen, Bo Skrifvars, ${ }^{*}$ Johan Edgren
}

\begin{abstract}
Clinical and serological findings of 16 patients with systemic lupus erythematosus (SLE) who had progressive cystic bone lesions were compared with a control group of 19 patients with SLE without radiological evidence of bone cysts. Central nervous system manifestations, synovitis, and other radiologically observed skeletal abnormalities were more prevalent in the patients with cysts than in the control group. Higher concentrations of $\mathrm{C}$ reactive protein, and a greater incidence of rheumatoid factor positivity were seen in the patients with cysts than in the control patients, but no other serological differences were found. It is suggested that patients with SLE with progressive cystic lesions form a subgroup of the syndrome characterised by an increased acute phase reaction.
\end{abstract}

Systemic lupus erythematosus (SLE) is a highly variable disorder characterised by several immunological aberrations. These are serologically reflected by the presence of antinuclear antibodies, circulating immune complexes, and reduced complement concentrations. Characteristically, the acute phase response is moderate even in active SLE. ${ }^{1-3}$ Involvement of the joints is the most common clinical manifestation of SLE, but objective signs of inflammation are often lacking. Also, skeletal abnormalities are uncommon. Radiological changes, when present, usually consist of soft tissue swelling and periarticular osteoporosis; cartilaginous and osseous destruction is rare. ${ }^{45}$ Recently, a deforming arthropathy of the hand in patients with SLE was characterised by Alarcon-Segovia et $a l .{ }^{6}$ We have observed a high prevalence of skeletal cystic lesions in patients with SLE. ${ }^{7}$ This study was undertaken to investigate further the possibility that patients with progressive cystic lesions differ clinically or serologically from patients without bone cysts. Our results suggest that the patients with cysts have an increased acute phase response and form a subset of SLE.

\section{Patients and methods}

Radiographs of the hands and feet were available from 125 consecutive patients whose disease fulfilled the revised American Rheumatism Association criteria for classification of SLE. ${ }^{8}$ The radiographs were taken routinely and the general results from that study have been reported. ${ }^{7}$ In this study patients with classical or definite rheumatoid arthritis were carefully excluded. The films were independently reviewed by three of us without knowledge of the clinical findings. Special attention was paid to possible changes in the cystic lesions during follow up. In 16 patients ( 15 female, one male) the lesions progressed during a mean follow up time of 4.3 years (range 1-9). The control group consisted of 19 consecutive patients (18 female, one male) without cysts and with sequential radiographs taken with at least one year's interval.

The mean age at onset of disease was 32 (SD 10) years in the group with cystic lesions and 25 (10) years in the control group. The mean duration of disease before the first radiographs in which cysts were seen was 9.8 years (range 1-26). In the control group the mean duration of disease until the last negative radiographs was $10 \cdot 3$ years $(2-20)$.

The presence of central nervous system symptoms, pleuritis or pericarditis, renal disorder, Raynaud's phenomenon, deep venous thrombosis, or synovitis at any time during the disease was recorded. Similarly, treatment with corticosteroids and immunosuppressive drugs was noted.

The laboratory data for the patients during the follow up period were screened and the highest values for $C$ reactive protein and cryoglobulin determinations, the highest antinuclear antibody (determined by immunofluorescence on rat liver), anti-DNA antibody (Farr assay), and rheumatoid factor (latex, Waaler-Rose) titres, and the lowest total haemolytic complement values were recorded. $C$ reactive protein values determined during obvious infections were excluded. All laboratory determinations were performed in the same laboratory.

Rank sums and rank correlations were calculated for the clinical findings and the laboratory values in the two groups.

\section{Results}

The cystic lesions were most commonly seen subchondrally in the heads of the second and third metacarpal bones or in the carpal bones (figure). Table 1 shows the occurrence of associated skeletal findings. Additional skeletal manifestations were more common in the patients with cysts $(p<0.01)$ than in the control patients. Erosions were found in four patients in the metatarsophalangeal joints and in the wrists in two. Early joint space narrowing was mainly seen in the radiocarpal joint; later all compartments of the wrist were involved. Subluxations were present in five patients with cysts and in one of the controls.

The patients with cystic bone lesions had 
A 59 year old woman with systemic lupus erythematosus of four years' duration who of four years duration who wrists. Previously normal hand radiographs showed a few cystic lesions in the wrists (a). Two years later there was definite progression with new cysts in the distal radius and metacarpal heads $(b)$
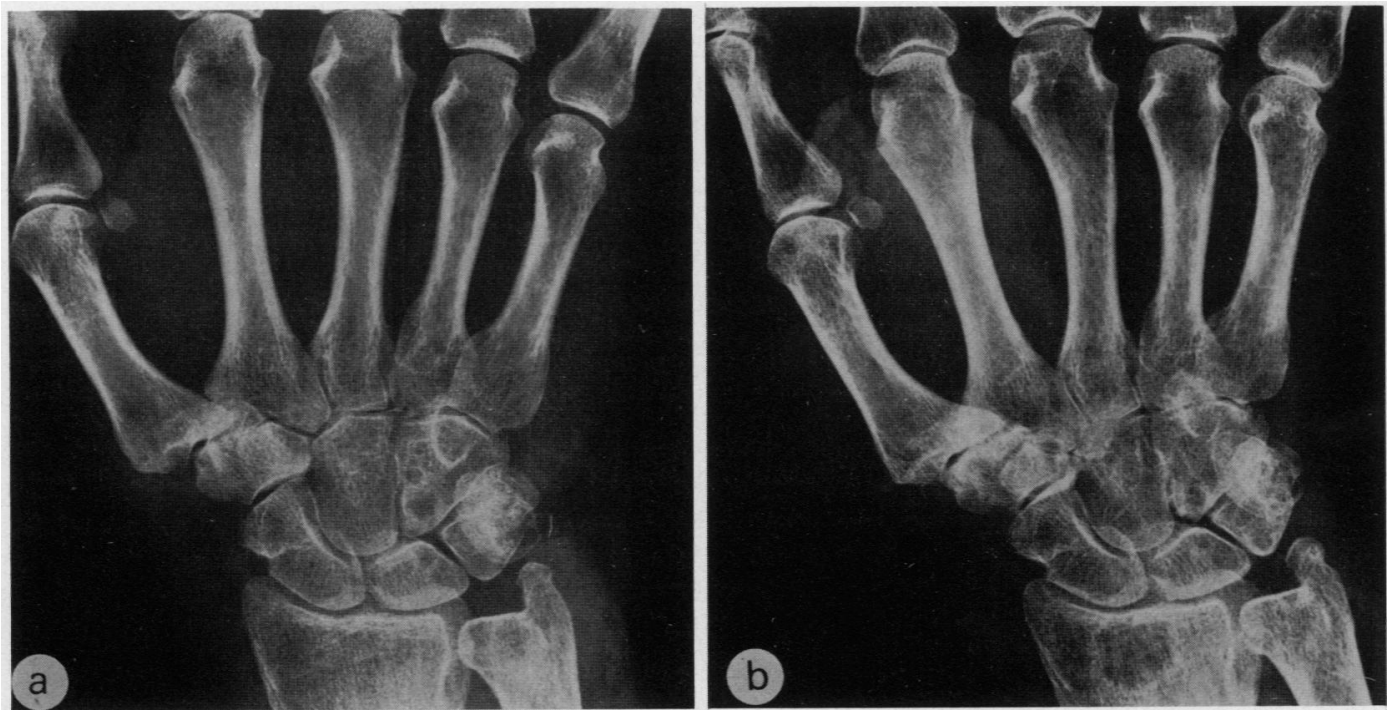

Table 1: Number (\%) of patients with and without cystic lesions with associated radiological findings

\begin{tabular}{lll}
\hline & $\begin{array}{l}\text { Patients with } \\
\text { cystic lesions } \\
(n=16)\end{array}$ & $\begin{array}{l}\text { Patients without } \\
\text { bone cysts } \\
(n=19)\end{array}$ \\
\hline Joint space narrowing & $8(50)$ & $1(5)$ \\
Erosions & $6(38)$ & 0 \\
Acral sclerosis & $5(31)$ & $2(11)$ \\
Alignment abnormalities & $5((31)$ & $1(5)$ \\
Periarticular calcifications & $3(19)$ & $1(5)$ \\
Osteonecrosis & $1(6)$ & 0 \\
Total radiological findings & $28^{*}$ & 5 \\
\hline
\end{tabular}

${ }^{*} \mathrm{p}<0 \cdot 01$.

Table 2: Number (\%) of patients with and without cystic lesions with clinical manifestations and number (\%) undergoing drug treatment (listed if positive at any time during the disease)

\begin{tabular}{lll}
\hline & $\begin{array}{l}\text { Patients with } \\
\text { cystic lesions } \\
(n=16)\end{array}$ & $\begin{array}{l}\text { Patients without } \\
\text { bone cysts } \\
(n=19)\end{array}$ \\
\hline Synovitis & $15(94)^{*}$ & $7(37)$ \\
Pleuritis/pericarditis & $7(44)$ & $4(21)$ \\
CNSt symptoms & $7(44)^{* *}$ & $1(5)$ \\
Renal disorder & $5(31)$ & $8(42)$ \\
Raynaud's phenomenon & $3(19)$ & $4(21)$ \\
Deep venous thrombosis & $3(19)$ & $4(21)$ \\
Dermatological manifestations $3(19)$ & $2(11)$ \\
Treatment with: & $3(100)$ & $16(8)$ \\
Corticosteroids & $16(100)$ & $9(47)$ \\
Immunosuppressive drugs & $1(6)^{*}$ & \\
\hline
\end{tabular}

${ }^{*} \mathrm{p}<0.01 ;{ }^{* *} \mathrm{p}<0.001$.

tCNS $=$ central nervous system.

Table 3: Summary of laboratory findings during the follow up. Values are given as No (\%) of patients

\begin{tabular}{|c|c|c|}
\hline & $\begin{array}{l}\text { Patients } \\
\text { with } \\
\text { cystic lesions } \\
(n=16)\end{array}$ & $\begin{array}{l}\text { Patients } \\
\text { without } \\
\text { bone cysts } \\
(n=19)\end{array}$ \\
\hline $\begin{array}{l}\text { Raised CRP† concentrations } \\
\text { Positive RF† } \\
\text { Decreased } \mathrm{CH}_{50} \text { concentrations } \\
\text { Cryoglobulin }>0.05 \mathrm{~g} / 1 \\
\text { Positive ANA }(>1 / 10) \\
\text { Positive anti-DNA antibodies }\end{array}$ & $\begin{array}{l}14 / 15(93)^{*} \\
5 / 16(31)^{*} \\
9 / 12(75) \\
7 / 12(58) \\
15 / 16(94) \\
14 / 16(88)\end{array}$ & $\begin{array}{r}11 / 19(58) \\
1 / 19(5) \\
16 / 18(89) \\
11 / 17(65) \\
17 / 19(89) \\
17 / 19(89)\end{array}$ \\
\hline
\end{tabular}

synovitis and evidence of central nervous system lupus (disturbances of mental functions, ocular dysfunction, movement disorders, paralysis, and severe headache) more often than the control patients $(p<0.01$ and $p<0.001$ respectively; table 2 ). Treatment with immunosuppressive drugs had been started more often in the patients without cystic lesions $(p<0 \cdot 01)$.

Table 3 gives a summary of the laboratory data. The patients with bone cysts had higher C reactive protein concentrations and were more often rheumatoid factor positive than the control patients $(\mathrm{p}<0.01)$. There was also a correlation between the presence of synovitis and high concentrations of $\mathrm{C}$ reactive protein and rheumatoid factor $(p<0.05)$.

\section{Discussion}

All the patients in this study fulfilled the revised American Rheumatism Association criteria for SLE, and there was no difference between the patients with progressive cystic bone lesions and the control patients without bone cysts in the presence of antinuclear antibodies or anti-DNA antibodies. The patients without cysts were followed up radiologically for at least as long as the patients with cysts. The skeletal cystic lesions differed from the characteristic marginal erosions of rheumatoid arthritis. Cystic erosions have been described in mixed connective tissue disease with a distribution similar to that found in this study. ${ }^{9}$ None of the patients fulfilled the criteria for mixed connective tissue disease, however. Some of the erosions seen might have developed owing to eruption of marginal cysts, but the metatarsophalangeal joint erosions were radiologically very similar to those seen in rheumatoid arthritis. Deforming arthropathy, resembling that described by Alarcon-Segovia et $a l,{ }^{6}$ was found more often in the patients with cysts than in the control patients.

We have previously speculated that the cystic lesions in SLE may be induced by vasculitis and impaired microcirculation. ${ }^{7}$ In this study we found no support for that hypothesis: cryoglobulins were equally common in the two groups and there was no difference in the 
concentrations of total haemolytic complement. Neither could we see any difference in the occurrence of clinical manifestations of vasculitis in the two patient groups. We have no explanation for the association between the occurrence of central nervous system lupus and the radiological findings. It may be of importance that the patients without skeletal cysts had been treated with immunosuppressive drugs more often than those with cystic lesions, even though the implications of this finding are unclear at present. There is no indication that treatment of deep venous thrombosis with heparin caused the cystic lesions.

Interestingly, the patients with cystic lesions showed objective signs of synovitis more often than the control patients. There was also a relation between the presence of synovitis and the acute phase reactant $C$ reactive protein. $C$ reactive protein concentrations are usually low even in active SLE, perhaps owing to an inoperative mechanism for the induction of the acute phase response. ${ }^{3}$ There is substantial evidence that the acute phase response is initiated by interleukin $1 .^{310} 11$ This is of particular interest as interleukin 1 stimulates bone resorption and cartilage destruction. ${ }^{10} 12$ Whether interleukin 1 mechanisms are operative in the induction of the cystic lesions in SLE remains, however, to be proved.

Clinically, the patients with progressive cystic lesions differed form the subset of SLE with early deforming arthropathy. ${ }^{6}$ A common feature was the high positivity for rheumatoid factor, but the other clinical manifestations were different. Sicca symptoms were common in the patients with deforming arthropathy, whereas our patients with cysts had evidence of central nervous system lupus. We suggest that patients with SLE with progressive skeletal cystic lesions form a subset of the syndrome characterised by an increased acute phase response. This subset of SLE seems to differ from that described by Alarcon-Segovia et $a l .^{6}$ The simultaneous presence of marginal erosions in the feet, also, suggests that these patients may represent an overlap syndrome between rheumatoid arthritis and SLE rather than a coexistence between the two entities.

The authors wish to express their gratitude to Gustaf Gripenberg $\mathrm{PhD}$, senior lecturer in mathematical analysis, for assistance in data analysis.

1 Honig S, Gorevic P, Weissman G. C-reactive protein in systemic lupus erythematosus. Arthritis Rheum 1977; 20

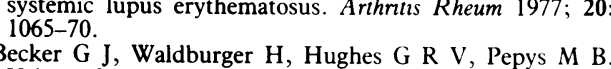

2 Becker G J, Waldburger $H$, Hughes G R V, Pepys M B.
Value of serum C-reactive protein measurement in the Value of serum $\mathrm{C}$-reactive protein measurement in the
investigation of fever in systemic lupus erythematosus. $A n n$ Rheum Dis 1980; 39: 50-2.

3 Pepys M B, Baltz M L. Acute phase proteins with special reference to $\mathrm{C}$-reactive protein and related proteins (pen taxins) and serum amyloid A protein. Adv Immunol 1983; 34: 141-212.

4 Resnick D. Systemic lupus erythematosus. In: Resnick D Niwayama G, eds. Diagnosis of bone and joint disorders. Vol II. Philadelphia: Saunders, 1981, 1180-203.

5 Lawson J. The joint manifestations of the connective tissue diseases. Semin Roentgenol 1982; 17: 25-38.

6 Alarcon-Segovia D, Abud-Mendoza C, Diaz-Jouanen E, Iglesias A, De los Reyes V, Hernandez-Ortiz J. Deforming arthropathy of the hands in systemic lupus erythematosus. 7 Rheumatol 1988; 15: 65-9.

7 Leskinen R H, Skrifvars B V, Laasonen L S, Edgren K J. Bone lesions in systemic lupus erythematosus. Radiology 1984; 153: 349-52.

8 Tan E M, Cohen A S, Fries J F, et al. The 1982 revised criteria for the classification of systemic lupus erythematosus. Arthritis Rheum 1982; 25: 1271-7.

9 Ramos-Niembro F, Alarcon-Segovia D, Hernandez-Oriz J Articular manifestations of mixed connective tissue disease. Arthritis Rheum 1979; 22: 43-51.

10 Dinarello C A. An update on human interleukin-1; from molecular biology to clinical relevance. $\mathcal{F}$ Clin Immunol molecular biolog

11 Dinarello C A, Mier J W. Lymphokines. N Engl f Med 1987; 317: $940-5$.

12 Maury C P J. Interleukin-1 and the pathogenesis of inflammatory diseases. Acta Med Scand 1986; 220: 291-4. 